\title{
The Kuroshio Extension Northern Recirculation Gyre: Profiling Float Measurements and Forcing Mechanism
}

\author{
Bo Qiu, Shuiming Chen, And Peter Hacker \\ Department of Oceanography, University of Hawaii at Manoa, Honolulu, Hawaii \\ Nelson G. Hogg and Steven R. Jayne \\ Woods Hole Oceanographic Institution, Woods Hole, Massachusetts \\ HideHARU SASAKI \\ Earth Simulator Center, JAMSTEC, Yokohama, Japan
}

(Manuscript received 25 September 2007, in final form 4 January 2008)

\begin{abstract}
Middepth, time-mean circulation in the western North Pacific Ocean $\left(28^{\circ}-45^{\circ} \mathrm{N}, 140^{\circ}-165^{\circ} \mathrm{E}\right)$ is investigated using drift information from the profiling floats deployed in the Kuroshio Extension System Study (KESS) and the International Argo programs. A well-defined, cyclonic recirculation gyre (RG) is found to exist north of the Kuroshio Extension jet, confined zonally between the Japan Trench $\left(\sim 145^{\circ} \mathrm{E}\right)$ and the Shatsky Rise $\left(\sim 156^{\circ} \mathrm{E}\right)$, and bordered to the north by the subarctic boundary along $\sim 40^{\circ} \mathrm{N}$. This northern $\mathrm{RG}$, which is simulated favorably in the eddy-resolving OGCM for the Earth Simulator (OFES) hindcast run model, has a maximum volume transport at $26.4 \mathrm{~Sv}$ across $159^{\circ} \mathrm{E}$ and its presence persists on the interannual and longer time scales. An examination of the time-mean $x$-momentum balance from the OFES hindcast run output reveals that horizontal convergence of Reynolds stresses works to accelerate both the eastward-flowing Kuroshio Extension jet and a westward mean flow north of the meandering jet. The fact that the northern RG is eddy driven is further confirmed by examining the turbulent Sverdrup balance, in which convergent eddy potential vorticity fluxes are found to induce the cyclonic RG across the background potential vorticity gradient field. For the strength of the simulated northern RG, the authors find the eddy dissipation effect to be important as well.
\end{abstract}

\section{Introduction}

A ubiquitous feature in the Northern Hemisphere subtropical ocean circulation is the existence of an anticyclonic recirculation gyre (RG) on the southern flank of the wind-driven western boundary current outflow. The southern RGs in the Kuroshio Extension (KE) and the Gulf Stream have been documented in many pioneering studies of these two current systems (e.g., Worthington 1976; Richardson 1985; Kawai 1972; Mizuno and White 1983). The RGs significantly enhance the eastward volume and heat transport of the western boundary currents (e.g., Wijffels et al. 1998) and their

Corresponding author address: Dr. Bo Qiu, Department of Oceanography, University of Hawaii at Manoa, 1000 Pope Rd., Honolulu, HI 96822.

E-mail: bo@soest.hawaii.edu variability has been recognized in recent years to be crucial in understanding the low-frequency midlatitude oceanic changes (Spall 1996; Qiu and Miao 2000; Schmeits and Dijkstra 2001; Dewar 2003; Hogg et al. 2005; Pierini 2006; Berloff et al. 2007; among others).

In the North Atlantic Ocean, various observations also reveal the presence of a RG north of the Gulf Stream jet between Cape Hatteras and the Grand Banks over a sloping bottom topography (Hogg et al. 1986; Hogg 1992). In contrast, evidence for a RG north of the Kuroshio Extension jet is fragmentary. Based on two years of moored current meter data along $152^{\circ} \mathrm{E}$, Schmitz et al. (1987) observed steady westward flows of $2 \sim 5 \mathrm{~cm} \mathrm{~s}^{-1}$ at the $1200-\mathrm{m}$ and $4000-\mathrm{m}$ depths flanking the narrow, eastward-flowing KE jet. Similar westwardrecirculating abyssal flows were found along $165^{\circ} \mathrm{E}$ by Schmitz (1987) and Joyce and Schmitz (1988). During the World Ocean Circulation Experiment (WOCE) 


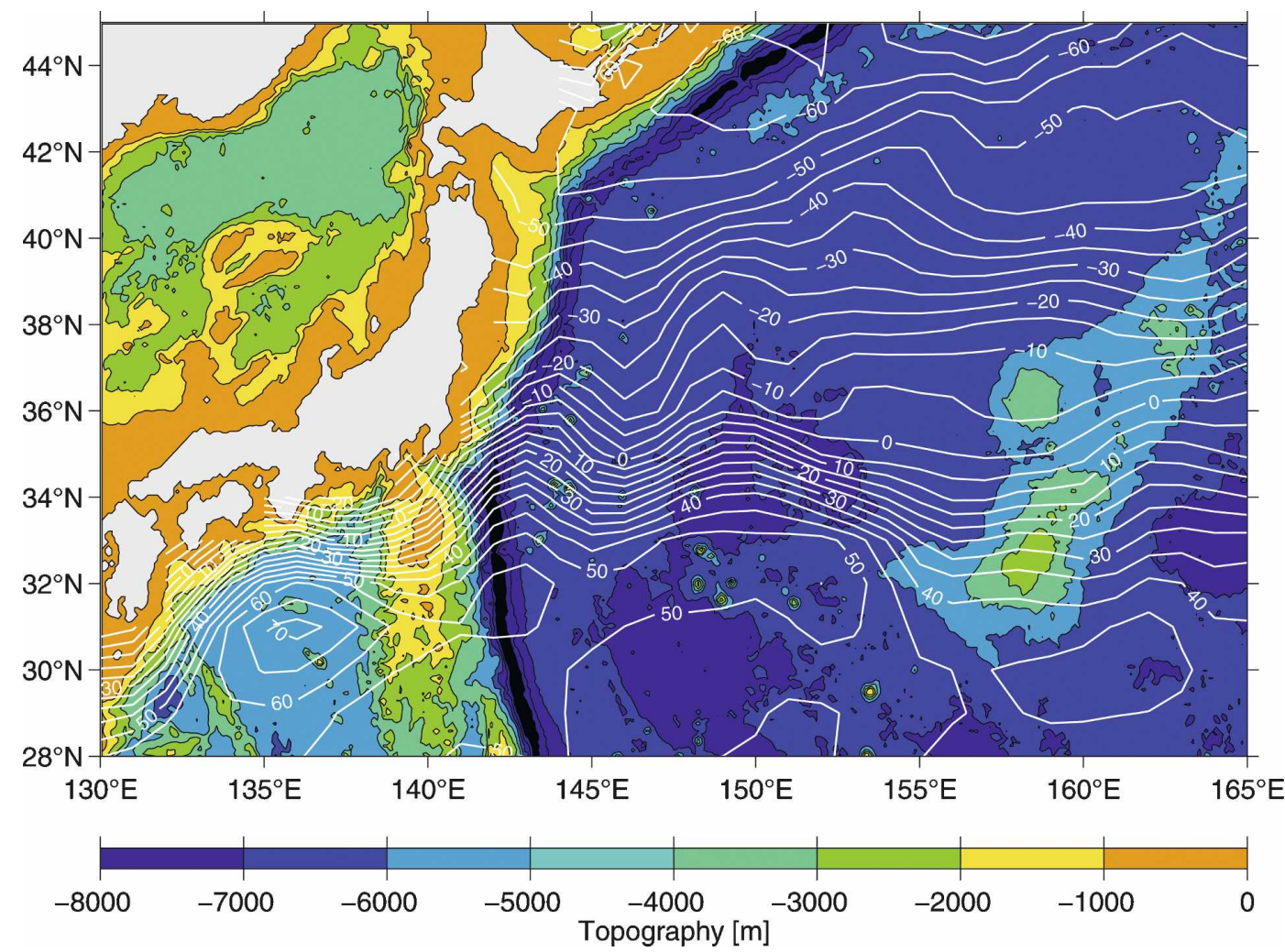

FIG. 1. Surface dynamic height field ( $\mathrm{cm}$, white contours) derived from surface drifter and satellite altimetric data by Niiler et al. (2003). Colored map shows the bathymetry based on Smith and Sandwell (1994). Major bathymetric features in the region include the Izu-Ogasawara Ridge along $140^{\circ} \mathrm{E}$ and the Shatsky Rise around $159^{\circ} \mathrm{E}$.

era, scattered moored current meter measurements at $4000 \mathrm{~m}$ have further captured westward mean flows at $36.4^{\circ} \mathrm{N}, 150.2^{\circ} \mathrm{E}$ and $38.4^{\circ} \mathrm{N}, 148.9^{\circ} \mathrm{E}$ by Owens and Warren $(2001)$, and at $38.0^{\circ} \mathrm{N}, 146.5^{\circ} \mathrm{E}$ and $38.0^{\circ} \mathrm{N}$, $145.5^{\circ} \mathrm{E}$ by Fujio and Yanagimoto (2005). In addition to the moored current meter measurements, westward abyssal flows north of the KE jet were also evident in a lowered acoustic Doppler current profiler (ADCP) transect along $152.5^{\circ} \mathrm{E}$ reported by Yoshikawa et al. (2004).

While our knowledge of the deep flows in the western North Pacific is increasing, an overall picture regarding the time-mean circulation of the KE's northern $\mathrm{RG}$ remains lacking. Unlike the RG south of the KE, there exists no surface expression revealing the presence of a northern RG in the KE system. For example, Fig. 1 shows the absolute mean surface dynamic height field determined by combining concurrent surface drifter, surface wind stress, and satellite altimeter data (Niiler et al. 2003). While a surface dynamic height plateau is clearly visible to the south of the KE jet centered along $\sim 32^{\circ} \mathrm{E}$, the surface dynamic height values decrease monotonically poleward north of the KE jet. In other words, clarifying the existence of a mean north- ern RG requires long-term, subsurface velocity measurements over the broad transition region between the $\mathrm{KE}$ and the subarctic boundary. ${ }^{1}$

A collaborative research program named the Kuroshio Extension System Study (KESS) was initiated in 2003. One of the objectives of KESS is to clarify the RG patterns as an integrated part of the Kuroshio Extension system. (Complete scientific objectives of KESS can be found online at http://www.uskess.org.) To achieve this objective, an array of moored profilers (MPs), current meters, pressure recording inverted echo sounders (PIES), and upward-looking ADCPs was deployed across the Kuroshio Extension jet from $32.5^{\circ}$ to $37.0^{\circ} \mathrm{N}$ near $146^{\circ} \mathrm{E}$ over the period from June 2004 to May 2006. In addition, a total of 48 APEX profiling floats were deployed during the KESS deploy-

\footnotetext{
${ }^{1}$ In Fig. 1, the "Subarctic Boundary" follows roughly the -35 $\mathrm{cm}$ surface dynamic height contour and it corresponds to an eastward flow along $\sim 40^{\circ}$ N. Farther to the north, the Subarctic Front corresponds to the $-55 \mathrm{~cm}$ surface dynamic height contour; it is accompanied by the northeastward-flowing Subarctic Current. A comprehensive review on the general circulation in the KuroshioOyashio transition region can be found in Yasuda (2003).
} 
ment and turnaround cruises in May/June 2004 and 2005 surrounding the MP/CM/PIES/ADCP array. The profiling floats have a parking depth at $1500 \mathrm{~m}$ and measure temperature-salinity profiles every 5 days. In the present study, we describe the mean circulation pattern at the 1500-m depth inferred from the profilingfloat drift trajectories. Results based on the moored $\mathrm{MP} / \mathrm{CM} / \mathrm{PIES} / \mathrm{ADCP}$ data will be reported in a separate paper (S. Jayne and N. Hogg 2007, personal communication).

In addition to the description of the inferred northern RG, we further explore in this study its formation mechanism with the aid of a global eddy-resolving ocean general circulation model (OGCM). Regarding the formation of the RG north of the Gulf Stream, two competing mechanisms have been put forth. The first regards the unstable Gulf Stream jet as an eddy energy source, with the time-mean northern RG being forced by radiating eddy fluxes (e.g., Holland and Rhines 1980; Hogg 1988; Jayne et al. 1996; Nakamura and Chao 2000). The second proposed mechanism emphasizes the importance of the sloping bottom topography and the intruding deep western boundary current (DWBC); in this scenario, the northern $\mathrm{RG}$ is generated by the downslope DWBC south of the Great Banks through bottom vortex stretching (e.g., Greatbatch et al. 1991; Zhang and Vallis 2007).

It is worth emphasizing that the oceanic conditions north of the KE are different from those north of the Gulf Stream in several important ways. First, the bottom topography north of the KE jet is largely flat with a depth of $\sim 6000 \mathrm{~m}$ (see Fig. 1). Prominent topographic features in the region include the deep Japan Trench parallel to the east coast of Japan and the Shatsky Rise located along $\sim 158^{\circ} \mathrm{E}$. These topographic features, as we will find in this study, do have a localized impact upon the middepth circulation. Second, no equivalent deep western boundary current, such as that driven by thermohaline processes in the subpolar North Atlantic, exists along the western boundary of the North Pacific Ocean. Third, rather than being confined to the north by a shallow continental shelf as in the North Atlantic, the region of the KE system is open to the north and is in direct contact with the western boundary current of the wind-driven subpolar gyre, that is, the Oyashio and its continuation, the subarctic boundary, and the Subarctic Front. Given these differences between the two current systems, a better description and exploration of the KE's northern RG can also help improve our understanding of the formation mechanism of the Gulf Stream's northern RG.

This paper is organized as follows. In section 2, we provide a detailed analysis of available profiling float data and describe the middepth mean circulation pattern around the KE jet. In section 3, we compare the observed mean circulation pattern with that obtained in an eddy-resolving OGCM output. The formation mechanism for the northern $\mathrm{RG}$ of the $\mathrm{KE}$ is examined in section 4 through momentum and potential vorticity budget analyses of the OGCM output. Section 5 summarizes our results from the present study.

\section{Float-derived middepth mean circulation}

During the KESS deployment cruise in May-June 2004, 20 APEX profiling floats were deployed in the $\mathrm{KE}$ region in order to capture the time-varying upperocean thermal structures and the flow pattern at the float parking depth of $1500 \mathrm{~m}$. A second set of 28 APEX floats was deployed during the turnaround cruise in May-June 2005. Maps of the float release locations from the two cruises can be found in Fig. 1 of Qiu et al. (2006, 2007), respectively. A profiling KESS float measures temperature-salinity $(T-S)$ at 72 prespecified pressure levels during its rise from the parking depth to the surface; the rise takes about $4.5 \mathrm{~h}$. While at the sea surface, the float transmits the $T-S$ data to the Advanced Research and Global Observation Satellite (ARGOS) system, and its position is "fixed" by ARGOS overpasses on an approximately hourly basis. On average, the float archives about seven position fixes during its $8.5 \mathrm{~h}$ on the surface. After diving to its parking depth, the float follows the 1500-m depth Lagrangian flow and it makes its next ascent to surface with a 5-day repeat cycle.

To derive the flow velocity at the parking depth, we follow Park et al. (2005) and utilize the float's ARGOS position fixes. Specifically, we estimate the float's diving and resurfacing locations by extrapolating the satellite position fixes by assuming a linear and inertial velocity model; the parking depth velocity is then obtained by dividing the distance between the diving and resurfacing locations by the time elapsed from the diving to resurfacing. There are two sources of error in this method of velocity estimation. The first is related to estimating the diving and resurfacing locations by extrapolating the float's position fixes. By analyzing a subset of the KESS floats and by withholding part of the ARGOS position fix information, we find that the error of the extrapolation has a median value of $881 \mathrm{~m}$ (Chen et al. 2007). The second source of error comes from the upper-ocean velocity shear that causes the float to drift during its ascending and descending periods. The size of this velocity shear can be evaluated from the float drifts at the sea surface and the parking depth. The median value for the drift due to the veloc- 


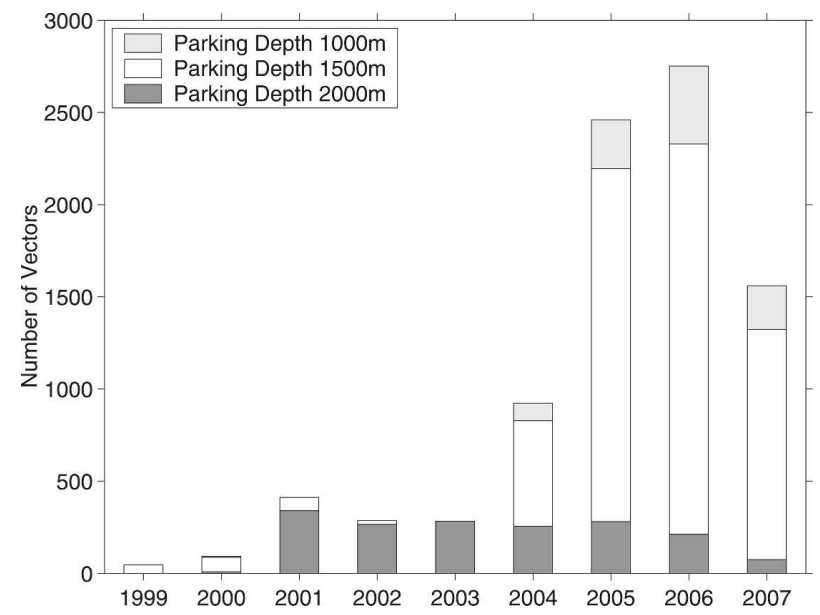

FIG. 2. Histogram of the available profiling float's dive-resurface pairs in the western North Pacific Ocean by years (as of November 2007) and parking depths. Out of the 6067 pairs with the parking depth at $1500 \mathrm{~m}$ in 2004-07, 5831 are from the KESS project. All other floats are from the international Argo program. Argo floats with parking depths shallower than $900 \mathrm{~m}$ are excluded from the present study.

ity shear is estimated at $2096 \mathrm{~m}$ (Chen et al. 2007). Assuming the above two errors are uncorrelated, we find that the uncertainty in the parking depth velocity estimated during a single float cycle is on the order of $0.8 \mathrm{~cm}^{-1}$.

As of November 2007, a total of 5831 dive-resurface position pairs are available from the KESS profiling floats. To improve the spatial and temporal coverage for the mean flow estimation, we further include in this study the profiling float data from the international Argo program in the region of our interest: $28^{\circ}-45^{\circ} \mathrm{N}$, $135^{\circ}-165^{\circ} \mathrm{E}$. As shown in Fig. 2, inclusion of the Argo profiling floats increases the overall number of float dive-resurface position pairs to 8813 over the 9 -yr period since 1999. Notice that the parking depths of the Argo profiling floats vary from 1000 to 1500 to $2000 \mathrm{~m}$. With the majority of floats drifting at the 1500-m depth, velocity values estimated from the floats drifting at other depths are adjusted to the 1500-m level by applying a correction based on climatological geostrophic shears calculated from the World Ocean Atlas 2001 (Conkright et al. 2002).

Figure 3 shows the individual velocity vectors at the 1500-m depth estimated from all available dive-resurface position pairs. In the figure, velocity vectors with a positive (negative) zonal component are indicated in red (blue). Despite the high level of eddy variability in the region, the presence of the eastward-flowing KE jet along $\sim 34^{\circ} \mathrm{N}$, the generally westward-moving flows on its two flanks, and the eastward flow associated with the subarctic boundary along $\sim 40^{\circ} \mathrm{N}$, can clearly be gleaned from the figure.

Using these available velocity estimates, we derive the time-mean flow pattern at the 1500-m depth by adopting the objective mapping technique of Bretherton et al. (1976). In mapping both $u$ and $v$ fields, we assume that the covariance function is in the form of a distance-weighted Gaussian function: exp $\left[-\left(\Delta x^{2}+\right.\right.$ $\left.\Delta y^{2}\right) / R^{2}$ ], where $\Delta x$ and $\Delta y$ are spatial distances in the $x$ and $y$ directions, and $R$ is the spatial decorrelation scale. Based on the inferred velocity vectors shown in Fig. 3, the value for $R$ is estimated to be $\sim 100 \mathrm{~km}$. Figure 4 shows the resultant mean velocity field objectively mapped from the velocity vectors presented in Fig. 3. Although it represents a nearly $9-y r$ mean flow field, Fig. 4 is biased to the period of 2005-06 when float measurements were most abundant (recall Fig. 2).

The position of the KE jet at the 1500-m depth tracks the mean surface KE jet very well (cf. Fig. 1). In Fig. 4, the crest of the second quasi-stationary meander of the $\mathrm{KE}$ jet, which exists nominally near $148^{\circ} \mathrm{E}$, appears relatively obscure. This obscurity is largely due to the fact that several intense, westward-propagating, coldcore eddies stalled south of the second quasi-stationary meander in 2005-06 (see Figs. 2 and 3 in Qiu et al. 2007), causing the local, float-derived KE path to have a southerly bias. Figure 4 shows that the KE path veers northward after encountering the Shatsky Rise near $158^{\circ} \mathrm{E}$ and that there is a broadening in the KE width downstream of the Shatsky Rise. Both of these features are discernible in the pattern of the surface KE jet shown in Fig. 1.

It is interesting to note that the subarctic boundary and the Subarctic Front have their respective middepth expressions in Fig. 4: the former corresponds to the eastward flow along $\sim 40^{\circ} \mathrm{N}$ and the latter, the northeastward flow along $\sim 43^{\circ} \mathrm{N}$. While both the subarctic boundary and the Subarctic Front have been considered in the past to be shallow upper-ocean features, the result of Fig. 4 indicates that their associated mean flows can reach at least to the $1500-m$ depth. Notice that a narrow southward current exists against the $1500-\mathrm{m}$ isobath east of Japan, which corresponds to the lower portion of the Oyashio (see Kono and Kawasaki 1997; Mitsudera et al. 2004). Offshore of this southward current exists a continuous northward flow that overrides the eastern flank of the sloping Japan Trench. While exhibiting little surface expression, this mean northward flow has been detected by moored current meter measurements and its existence has been regarded as a rectified along-slope current driven by the underlying Japan Trench slope (Owens and Warren 2001; Fujio and Yanagimoto 2005). 


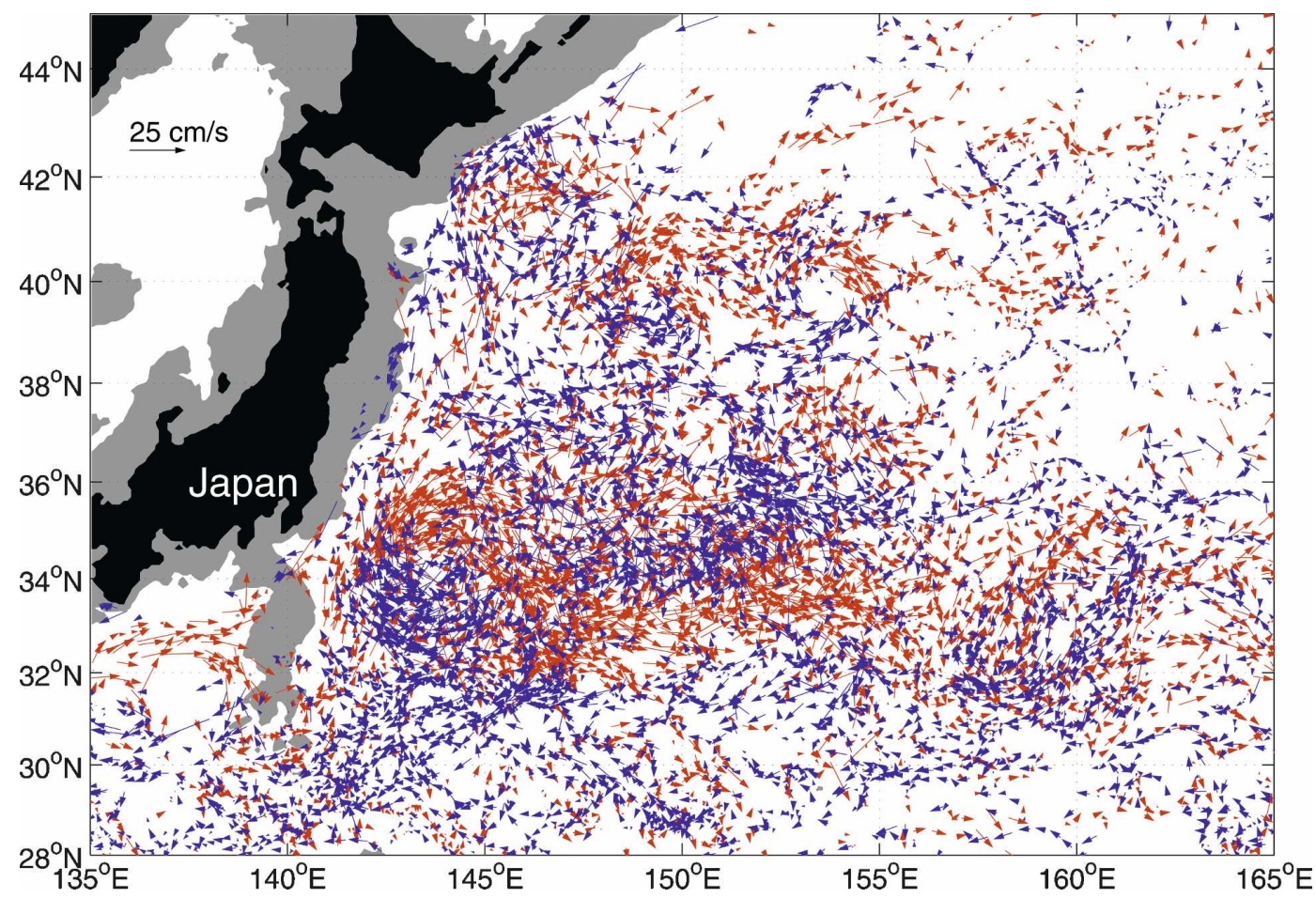

FIG. 3. Velocity vectors at the $1500-\mathrm{m}$ depth estimated from the 8813 available pairs of ascending-descending float positions. Floats with the parking depth at 1000 and $2000 \mathrm{~m}$ have their velocity values adjusted according to local, climatological geostrophic shears. Velocity vectors with an eastward (westward) component are plotted in red (blue).

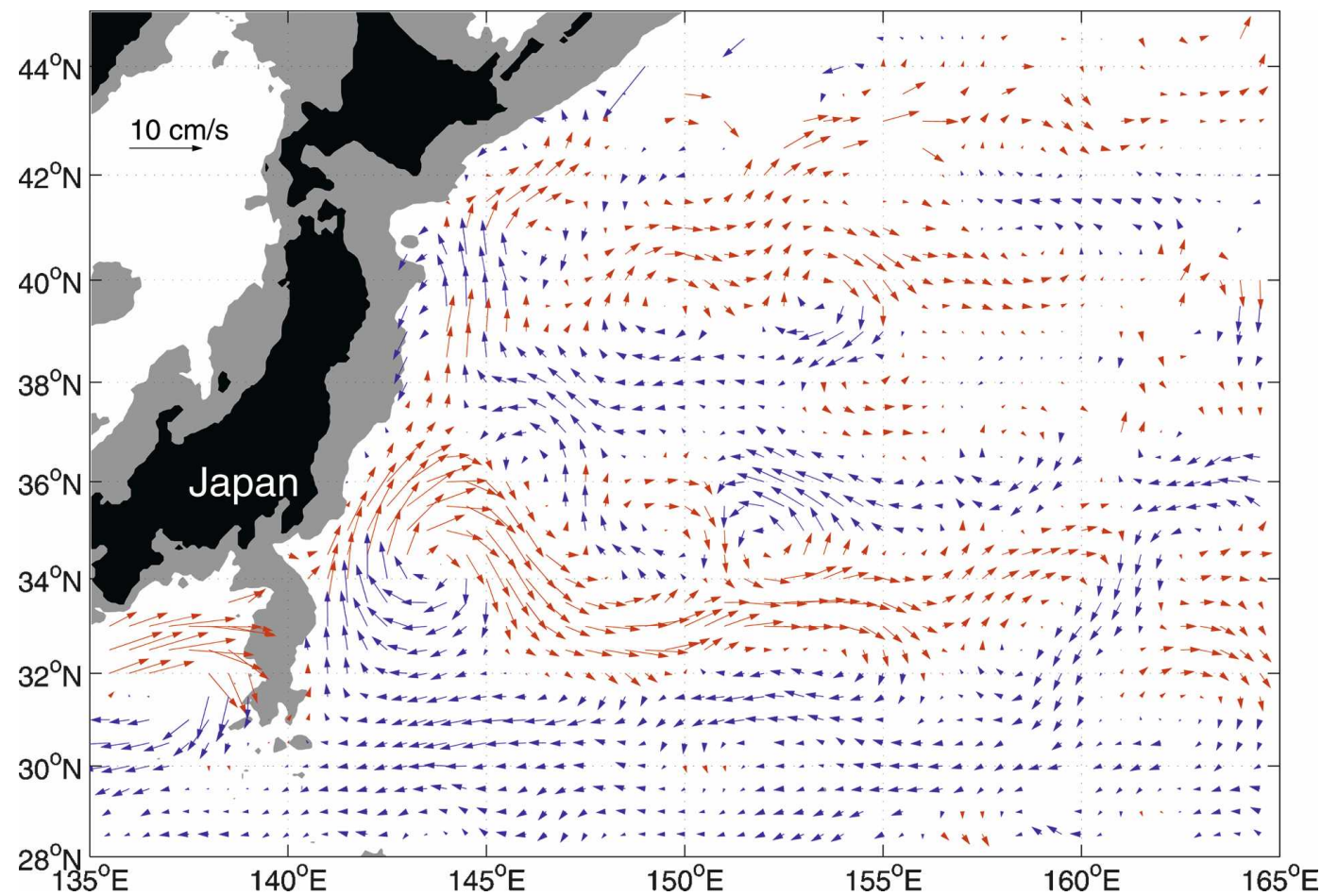

FIG. 4. Time-mean velocity field at the 1500-m depth objectively mapped from the available velocity vectors shown in Fig. 3. See text for the objective mapping procedure. Velocity vectors with an eastward (westward) component are plotted in red (blue). 
Persistent westward flows are seen in Fig. 4 to exist south of the KE jet. These westward flows constitute part of the KE's southern RG and their existence is evident in the surface dynamic height field shown in Fig. 1 as well. In between the KE jet and the subarctic boundary, broadscale westward flows, corresponding to the KE's northern recirculation, are clearly discernible in Fig. 4. Although abyssal westward flows have been observed at several locations in this region (see references cited in the introduction), Fig. 4 provides the first, time-mean flow pattern that delineates the horizontal extent of the northern RG in the KE system. Unlike its southern counterpart, the northern RG shows no expression in the mean surface dynamic height field.

\section{Middepth circulation in the OFES simulation}

To clarify the nature and formation mechanism of the northern RG in this study, we examine model results from a multidecadal hindcast run of the OGCM for the Earth Simulator (OFES). In this section, we explore the model's realism in comparison with the float-inferred middepth circulation pattern. The representativeness of Fig. 4 as the long-term mean flow pattern at the 1500-m depth and the three-dimensional structure of the KE's northern RG are investigated using the model's output.

The OFES model covers the global domain from $75^{\circ} \mathrm{S}$ to $75^{\circ} \mathrm{N}$; it has an eddy-resolving horizontal resolution of $0.1^{\circ}$ and 54 vertical levels. The model code is based on Modular Ocean Model version 3 (MOM3), modified for optimal performance by the Earth Simulator of Japan (Sasaki et al. 2008). The model was spun up for 50 years with monthly climatological atmospheric forcing from the National Centers for Environmental Prediction-National Center for Atmospheric Research (NCEP-NCAR) reanalysis (Kistler et al. 2001). This climatological run was followed by a $55-\mathrm{yr}$ hindcast integration for the period 1950-2004 using the NCEP-NCAR reanalysis daily-mean forcing data. In our present study, the model output from the 55-yr hindcast run was analyzed. For more details on the OFES model, such as its initial/boundary conditions and subgrid-scale eddy parameterizations, readers are referred to Nonaka et al. (2006).

Figure 5a shows the flow field at the 1500-m depth averaged from 2000 to 2004 using the OFES hindcast run. This 5-yr duration overlaps with the period of the profiling float measurements although, as we noted in section 2, the float-inferred flow field of Fig. 4 is likely biased to 2005-06. Despite this possible bias, the modeled flow pattern compares favorably to the observed flow field. All major zonal flows identified in Fig. 4, that is, the KE jet, its northern and southern westward re- circulating flows, and the eastward flows associated with the subarctic boundary and the Subarctic Front) can be located in Fig. 5a. Along the 1500-m isobath east of Japan, the southward intruding Oyashio appears less clear in the model than in Fig. 4, although the OFES hindcast captures well the northward flow overriding the eastern flank of the sloping Japan Trench. Notice that the flow pattern appears smoother in Fig. 5a than Fig. 4; this is because the model result was based on the full 5-yr averaging, whereas Fig. 4 was based on the temporally and spatially irregular float measurements.

It is worth emphasizing that the mean flow pattern shown in Fig. 5a does not depend sensitively on the period over which the averaging is taken. Averaging the flow field over the entire 55-yr period from 1950 to 2004, for example, results in a flow pattern at the 1500-m depth (Fig. 5b) quite similar to that of Fig. 5 a. $^{2}$ To illustrate this point further, we plot in Fig. 6 the $1500-\mathrm{m}$ depth zonal velocity as a function of latitude and time along $150^{\circ} \mathrm{E}$ over the 55 -yr hindcast period. While the instantaneous flows are clearly influenced by transient mesoscale eddy signals, all of the major zonal flows consistently appear once an interannual or longer time scale, averaging is taken. This model result is important as it suggests that, while the accumulation of the profiling float data in the coming years will undoubtedly improve the inferred middepth flow pattern, the overall picture presented in Fig. 4 is likely to remain unchanged.

To obtain a three-dimensional picture of the northern RG, we plot in Fig. 7 meridional sections of the mean zonal velocity along $145^{\circ} \mathrm{E}, 150^{\circ} \mathrm{E}$, and $155^{\circ} \mathrm{E}$, respectively, from the OFES hindcast run. The time averaging, as in Fig. 5a, is taken from 2000 to 2004. The $145^{\circ} \mathrm{E}$ section is located just east of the northward flow overriding the Japan Trench and is close to the western edge of the northern RG. Abyssal flows (below $2000 \mathrm{~m}$ ) underneath the KE jet and the northern RG along this section are weak and fragmented. The volume transport associated with the northern $\mathrm{RG}$ across $145^{\circ} \mathrm{E}$ is 9.2 $\mathrm{Sv}\left(\mathrm{Sv} \equiv 10^{6} \mathrm{~m}^{3} \mathrm{~s}^{-1}\right.$; see the dashed line in Fig. 8). The northern RG, with the maximum westward flow centered on $38.5^{\circ} \mathrm{N}$, becomes fully developed along $150^{\circ} \mathrm{E}$. Compared to the upstream $145^{\circ} \mathrm{E}$ section, Fig. $7 \mathrm{~b}$ shows that both the KE jet and the northern RG are more vertically coherent, or equivalent barotropic. The volume transport of the northern RG increases to 26.4 $\mathrm{Sv}$ across the $150^{\circ} \mathrm{E}$ section. The $155^{\circ} \mathrm{E}$ section is located west of the Shatsky Rise where the path of the

\footnotetext{
${ }^{2}$ Due to the longer-period averaging, the magnitude of the flow vectors in Fig. $5 \mathrm{~b}$ becomes smaller and this is particularly true for the $\mathrm{KE}$ jet downstream of $152^{\circ} \mathrm{E}$.
} 
(a) OFES 2000-2004

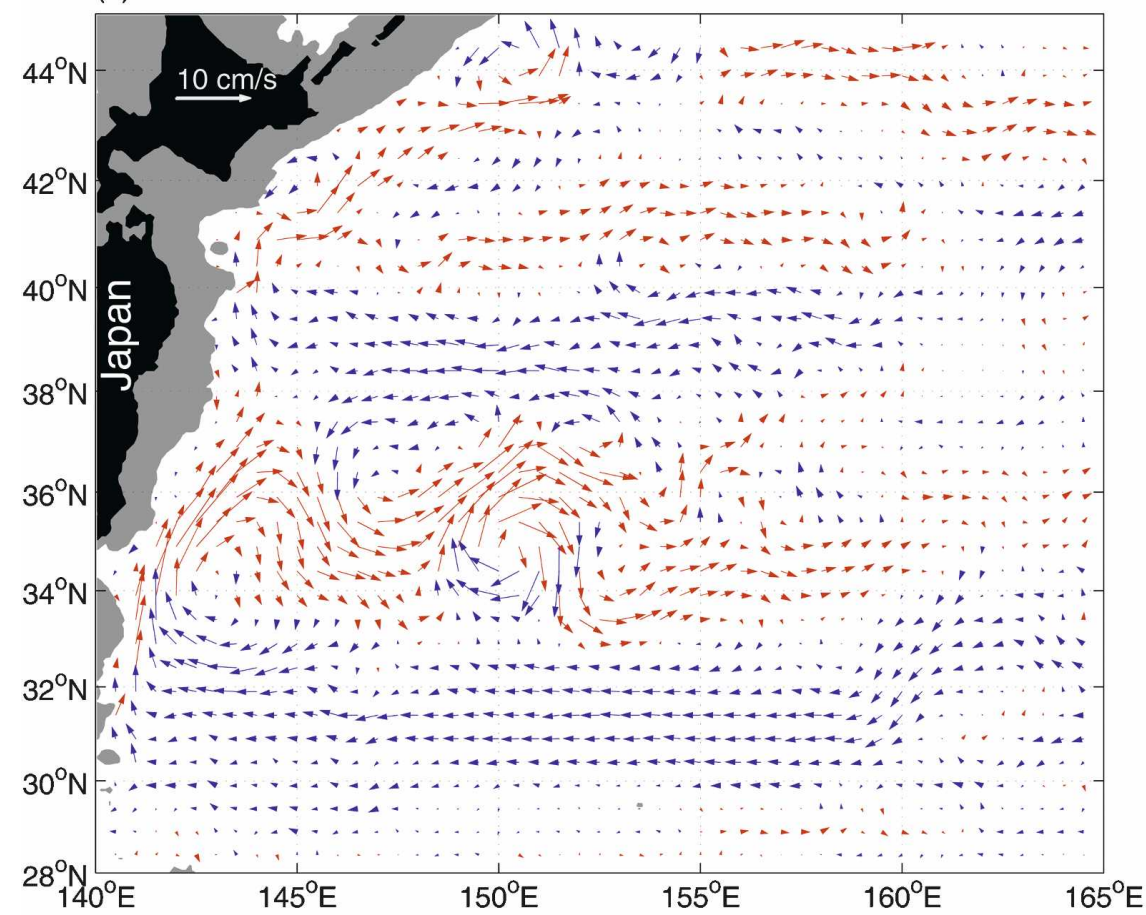

(b) OFES 1950-2004

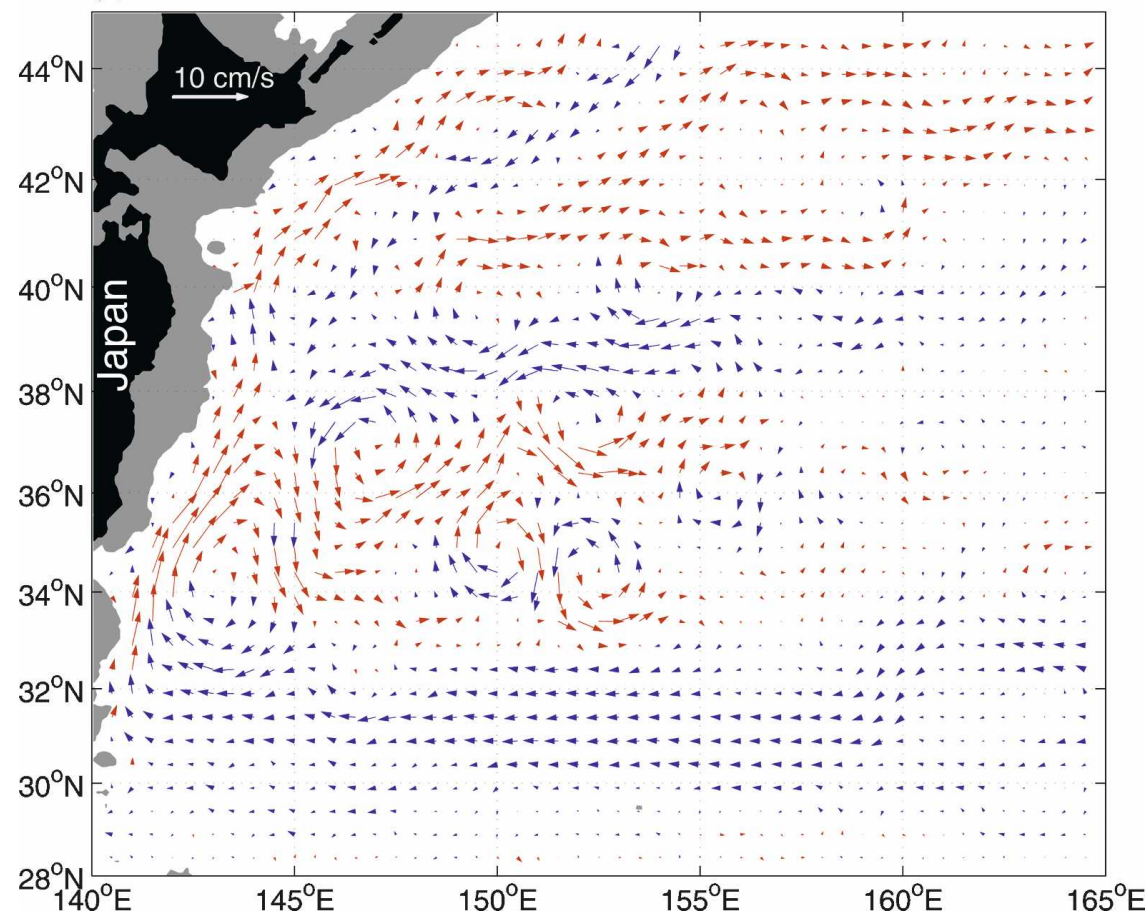

FIG. 5. Mean velocity field at the 1500-m depth averaged in (a) 2000-04 and (b) 1950-2004 from the OFES hindcast run. Velocity vectors are subsampled from the original $0.1^{\circ} \times 0.1^{\circ}$ model grid. Vectors with an eastward (westward) component are plotted in red (blue). 


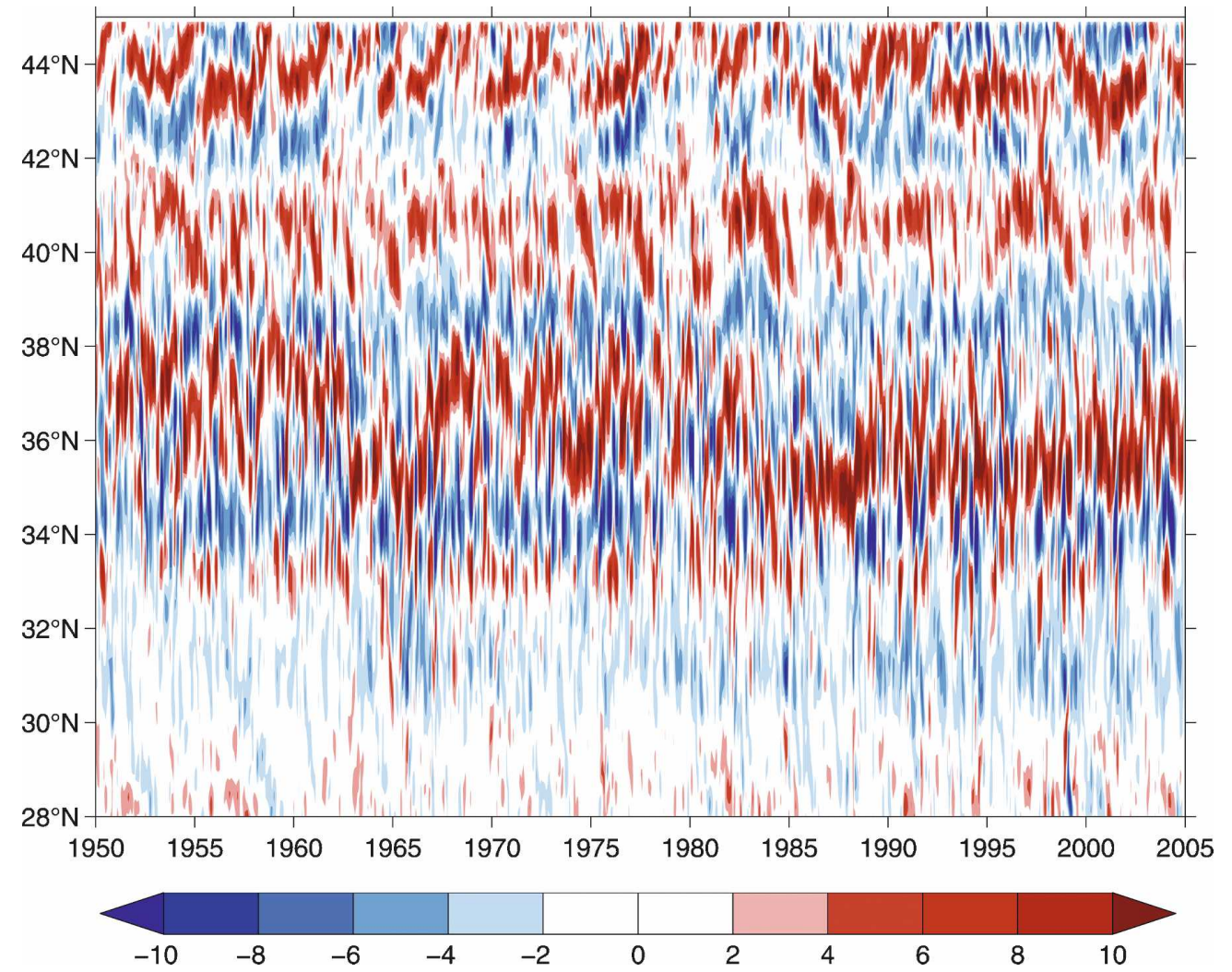

FIG. 6. Zonal velocity along $150^{\circ} \mathrm{E}$ at the $1500-\mathrm{m}$ depth as a function of time and latitude based on the model output of the OFES hindcast run from 1950 to 2004.

mean KE jet veers northeastward (recall Figs. 4 and 5). Accompanying the broadening of the KE jet along this section, the volume transport of the northern RG drops to $20.9 \mathrm{~Sv}$ (see the gray line in Fig. 8). Downstream of the Shatsky Rise, the width of the KE jet broadens further and the northern RG becomes no longer well defined; the westward flow north of the KE along $160^{\circ} \mathrm{E}$, for example, has a volume transport less than 5 $\mathrm{Sv}$ (figure not shown).

In concluding this section, we note that the net volume transport values across the $28^{\circ}-45^{\circ} \mathrm{N}$ segment shown in Fig. 8 (e.g., $33 \mathrm{~Sv}$ across $150^{\circ} \mathrm{E}$ ) agrees well with the Sverdrup transport values calculated from the wind stress curl data of the NCEP-NCAR reanalysis. This agreement indicates that the wind-driven circulation dominates the large-scale flows in the western North Pacific and that the enhanced eastward transport of the mean $\mathrm{KE}$ jet (e.g., $93 \mathrm{~Sv}$ across $150^{\circ} \mathrm{E}$ ) is due to the presence of the neighboring southern and northern RGs.

\section{Formation mechanism of the northern RG}

With the OFES hindcast run simulating well the observed middepth circulation around the KE jet, we use the high-resolution model output in this section to explore the formation mechanism of the detected northern RG. Given the essentially flat regional bottom topography beneath the northern RG, we hypothesize that the northern RG is driven by eddy fluxes related to the unstable KE jet. The fact that the KE jet is a highly unstable system in the region of $140^{\circ}-160^{\circ} \mathrm{E}$ has been investigated quite extensively. Readers interested in this topic are referred to Qiu and Chen (2005) and Taguchi et al. (2007) for references and recent analyses.

To keep this paper concise, we limit our presentation of the model analysis results to the isopycnal surface $27.575 \sigma_{\theta}$. Instead of an isobaric surface, an isopycnal surface is used in this section because the isopycnal coordinates annihilate the vorticity-generating solenoidal term and are a natural choice to conduct budget analysis of potential vorticity (Vallis 2006). In the region of our interest, the $27.575 \sigma_{\theta}$ isopycnal surface has a depth ranging from 1300 to $1700 \mathrm{~m}$ and a mean value at $1500 \mathrm{~m}$ (see Fig. 9a). As we noted in section 3, the modeled mean flow pattern at this depth agrees well with the profiling float result and is representative of the flows below the main thermocline (Fig. 7). Because of the weak vertical shear, the mean velocity $\overline{\mathbf{u}}$ on the 
(a) along $145^{\circ} \mathrm{E}$

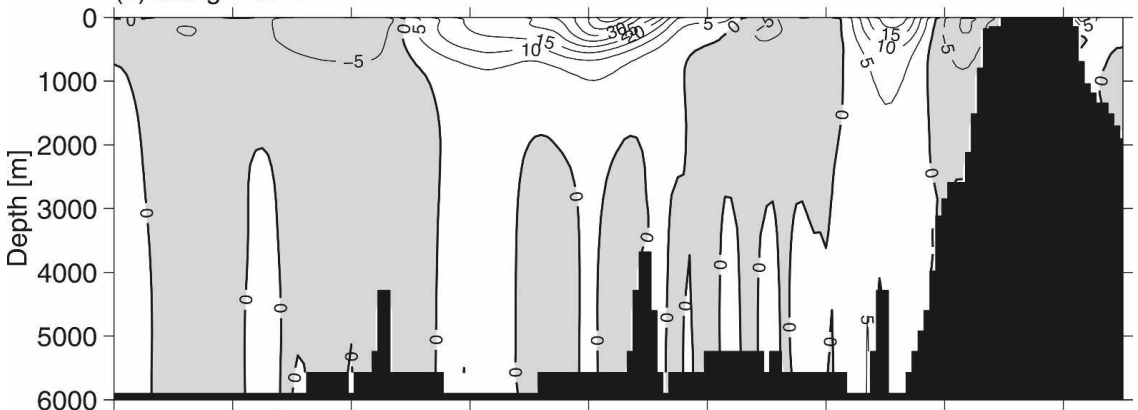

(b) along $150^{\circ} \mathrm{E}$

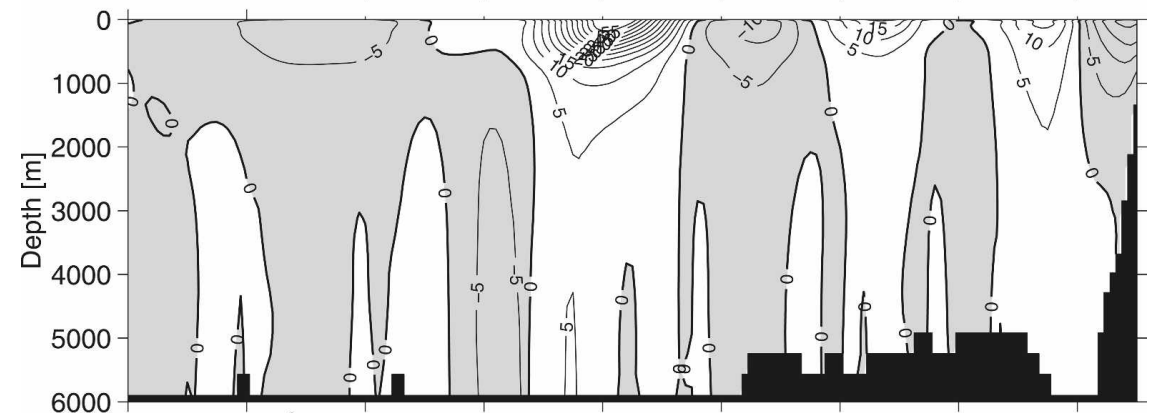

(c) along $155^{\circ} \mathrm{E}$

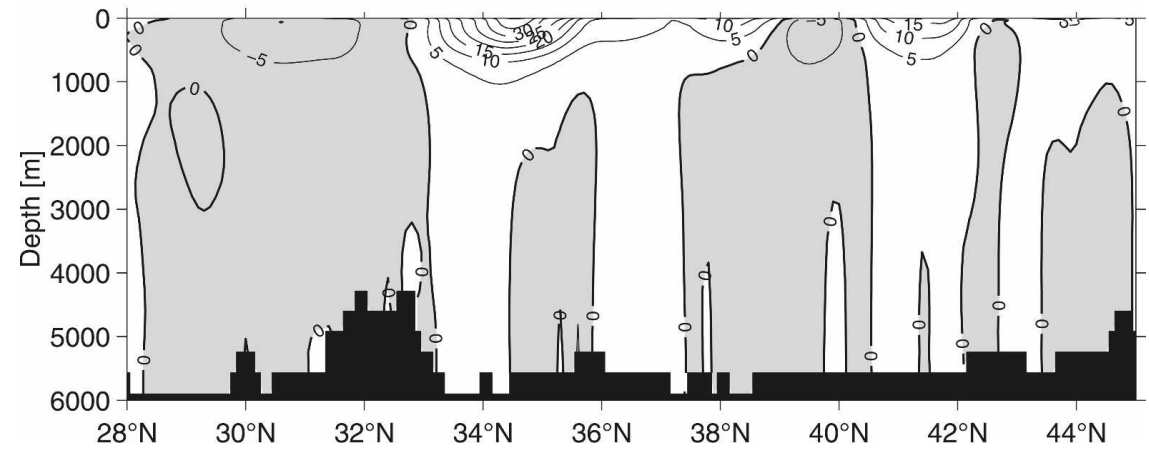

FIG. 7. Zonal velocity profiles across (a) $145^{\circ} \mathrm{E}$, (b) $150^{\circ} \mathrm{E}$, and (c) $155^{\circ} \mathrm{E}$ averaged in 2000-04 from the OFES hindcast run. Contour unit in $\mathrm{cm} \mathrm{s}^{-1}$; shaded areas indicate westward mean flows.

$27.575 \sigma_{\theta}$ surface from the 2000-04 OFES output looks very similar to that shown in Fig. 5a. Instead of showing this $\overline{\mathbf{u}}$ field, we plot in Fig. 9b its associated geostrophic streamfunction $\bar{\Psi}$ field on the $27.575 \sigma_{\theta}$ surface for the purposes of following discussions. In Fig. 9b, the northern RG corresponds well to the region north of the KE jet where $\bar{\Psi}<-1000 \mathrm{~m}^{2} \mathrm{~s}^{-1}$. Notice that due to the equivalent barotropic nature of the mean flow field, the spatial pattern of the $\bar{\Psi}$ field somewhat resembles the isopycnal depth field of Fig. 9a.

Figure 10 shows the mean potential vorticity (PV) field $\bar{Q}$ on the $27.575 \sigma_{\theta}$ surface. Here instantaneous $Q$ is defined by

$$
Q=f_{o}+\beta y+\zeta+f_{o} \frac{\partial \sigma_{\theta} / \partial z}{\partial\left\langle\bar{\sigma}_{\theta}\right\rangle / \partial z},
$$

where $\zeta$ denotes the relative vorticity, $f_{o}$ the Coriolis parameter at the reference latitude $\left(35^{\circ} \mathrm{N}\right.$ here $), \beta$ the latitudinal gradient of $f, \sigma_{\theta}$ the potential density, and $\left\langle\bar{\sigma}_{\theta}\right\rangle$ the potential density averaged in time and space (i.e., the domain of Fig. 10), respectively. Thus defined, $\left\langle\bar{\sigma}_{\theta}\right\rangle$ is a function of $z$ only. The PV definition of Eq. (1) has been used by Kagimoto and Nakamura (2007, manuscript submitted to Dyn. Atmos. Oceans) in their study of quasigeostrophic transient wave activity and fluxes in the North Pacific Ocean basin. On the broad scale, Fig. 10 reveals that $\bar{Q}$ increases with the latitude due to the planetary vorticity $\beta y$. In the region surrounding the $\mathrm{KE}$ jet, the stretching vorticity term in Eq. (1) works to reduce the meridional PV gradient $\partial \bar{Q} / \partial y$ and its effect is clearly identifiable in Fig. 10. The fact that $\partial \bar{Q} / \partial y$ is reduced in the vicinity of the KE jet has 


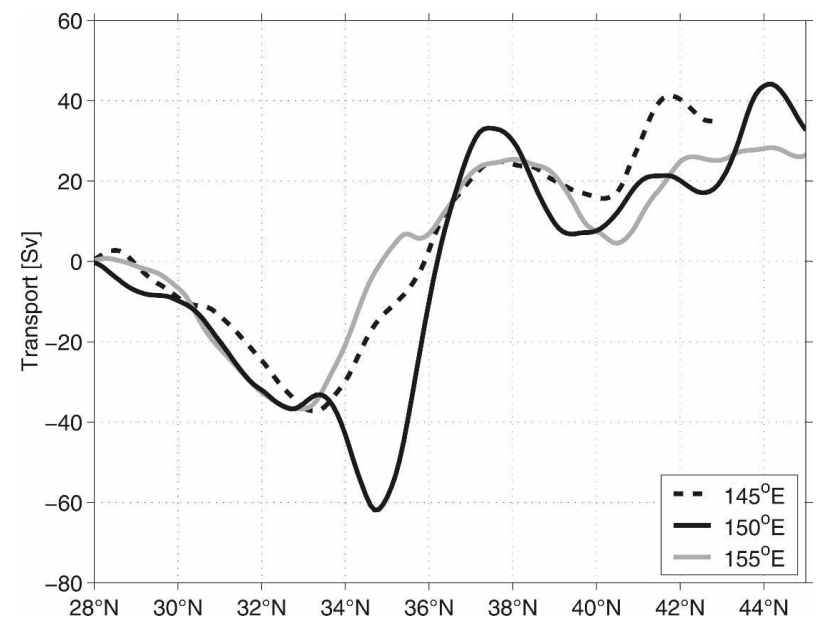

FIG. 8. Accumulative eastward volume transport values across $145^{\circ}, 150^{\circ}$, and $155^{\circ} \mathrm{E}$, respectively. The zonal velocity profiles across these sections are shown in Fig. 7. The reference latitude is $28^{\circ} \mathrm{N}$.

been noted in the previous study of the PV distribution in the North Pacific by Talley (1988). Superimposed on Fig. 10 by the white lines are the geostrophic streamfunction contours shown in Fig. 9b. It is important to emphasize that the $\bar{\Psi}$ and $\bar{Q}$ contours are not fully parallel to each other, implying that the mean circulation on this isopycnal surface is not exactly inertial and that other physical processes, such as eddy forcing and dissipation, must play a role in the determination of the $\overline{\mathbf{u}}$ field.

To quantify the effect of the eddy forcing, we first evaluate the convergence of the Reynolds stresses in the $x$-momentum equation:

$$
\frac{\partial \bar{u}}{\partial t} \sim-\nabla \cdot\left(\overline{u^{\prime} \mathbf{u}^{\prime}}\right),
$$

that is, the rhs of Eq. (2) (see Fig. 11). Here an overbar denotes the mean value averaged from 2000 to 2004 and a prime denotes the deviation from the mean. As indicated in Eq. (2), a positive (negative) Reynolds stress convergence tends to enhance (weaken) the mean zonal flow. Although the result in Fig. 11 is somewhat patchy due to the meandering KE jet, a persistent picture is, nevertheless, detectable. Specifically, along the path of the KE jet (i.e., along the continuous $\bar{\Psi}=$ 0 contour around $35^{\circ} \mathrm{N}$ in Fig. 11), the Reynolds stress convergence is, by and large, positive, indicating the eastward-flowing KE jet is being accelerated by the lateral eddy momentum flux forcing. One exception occurs over the Shatsky Rise near $156^{\circ}-159^{\circ} \mathrm{E}$ where the Reynolds stress convergence has a large negative value. Northwest of this negative Reynolds stress convergence region, a large positive Reynolds stress convergence area exists with its center at $37.5^{\circ} \mathrm{N}, 156^{\circ} \mathrm{E}$. This area, as we noted in Fig. 5a, corresponds to where the KE jet bifurcates and forms its northern branch. The result of Fig. 11, thus, suggests that the eddy momentum forcing around the Shatsky Rise works to accelerate the northern branch of the KE jet and weakens, at the same time, the southern branch. This result regarding the importance of eddy forcing in generating the northern KE branch is consistent with the high-resolution model study by Hurlburt and Metzger (1998). On the two sides of the meandering KE jet, Fig. 11 reveals that the Reynolds stress convergence has largely negative values, indicating the laterally radiating eddy momentum fluxes work to accelerate the recirculating westward mean flows. This result, based on the model's Reynolds stress analysis, thus supports the hypothesis that the northern $\mathrm{RG}$ is eddy driven.

It is also instructive to examine the eddy's impact on the northern RG from the PV point of view. Specifically, we are interested in whether the mean northern $\mathrm{RG}$ could be understood as resulting from the turbulent Sverdrup balance theorized by Rhines and Holland (1979):

$$
\overline{\mathbf{u}} \cdot \nabla \bar{Q} \simeq-\nabla \cdot\left(\overline{\mathbf{u}^{\prime} Q^{\prime}}\right),
$$

where the perturbation $\mathrm{PV} Q^{\prime}$, following Eq. (1), is given by

$$
Q^{\prime}=(\zeta-\bar{\zeta})+f_{o}\left(\frac{\partial \sigma_{\theta}}{\partial z}-\frac{\partial \bar{\sigma}_{\theta}}{\partial z}\right) / \frac{\partial\left\langle\bar{\sigma}_{\theta}\right\rangle}{\partial z} .
$$

Using the geostrophic streamfunction $\bar{\Psi}$, the lhs of Eq. (3) can also be written as $J(\bar{\Psi}, \bar{Q})$, where $J$ is the Jacobian operator. Physically, Eq. (3) relates the convergence of eddy PV fluxes to the mean flow generation across the mean PV gradient. In Fig. 12, we compare the distributions of $J(\bar{\Psi}, \bar{Q})$, and $-\nabla \cdot\left(\overline{\mathbf{u}^{\prime} Q^{\prime}}\right)$ on the $27.575 \sigma_{\theta}$ surface. Despite the dominance by patchy small-scale features, a favorable correspondence between these two terms is visually discernible. To examine this correspondence in a more quantitative way, we present in Fig. 13 a scatterplot of $J(\bar{\Psi}, \bar{Q})$, versus $-\nabla \cdot\left(\overline{\mathbf{u}^{\prime} Q^{\prime}}\right)$ inside the northern RG region of our interest (defined as the area where $\bar{\Psi}<1000 \mathrm{~m}^{2} \mathrm{~s}^{-1}$ in Fig. 9b). The linear correlation coefficient between the two terms is 0.45 . While confirming the general validity of the turbulent Sverdrup balance, the result of Fig. 13 also underlines the importance of the eddy dissipation term neglected in Eq. (3). Note that the linear correlation coefficient value at 0.45 between the $J(\bar{\Psi}, \bar{Q})$, and $-\boldsymbol{\nabla} \cdot\left(\overline{\mathbf{u}^{\prime} Q^{\prime}}\right)$ terms is typical for the other areas as well.

Like for the wind-driven Sverdrup transport streamfunction, the convergent eddy flux-driven mean flow 
(a) Depth of $\sigma_{\theta}=27.575 \mathrm{~kg} / \mathrm{m}^{3}$

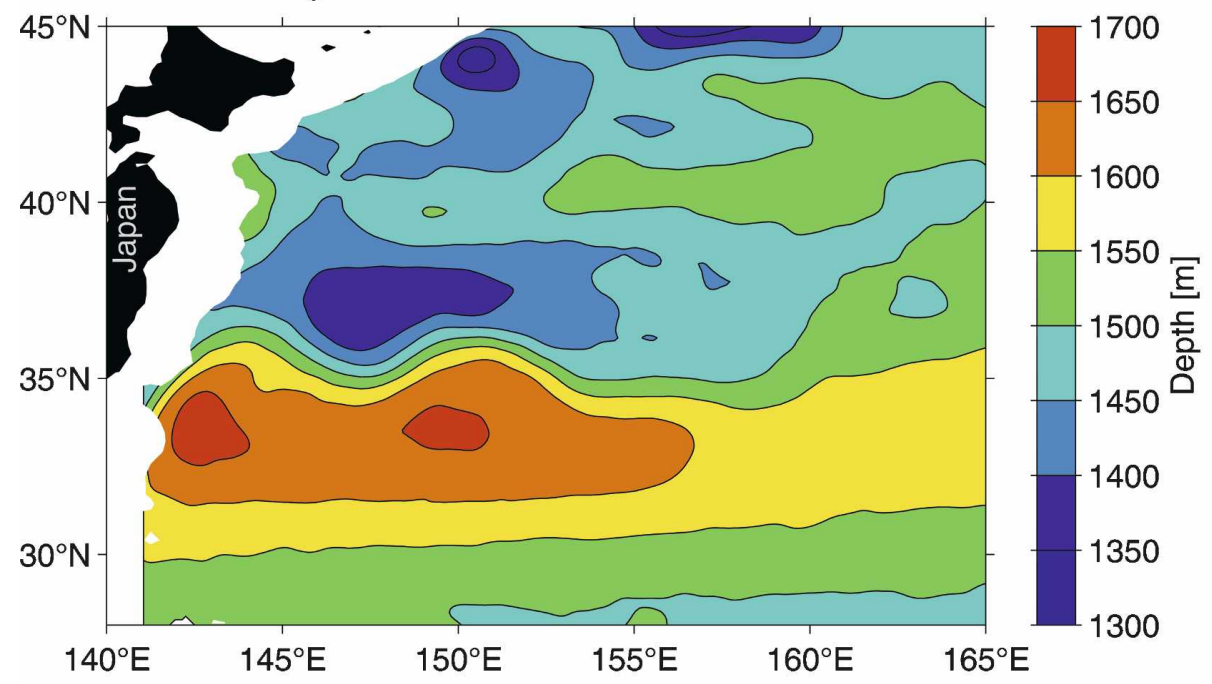

(b) Geostrophic Streamfunction on $\sigma_{\theta}=27.575 \mathrm{~kg} / \mathrm{m}^{3}$

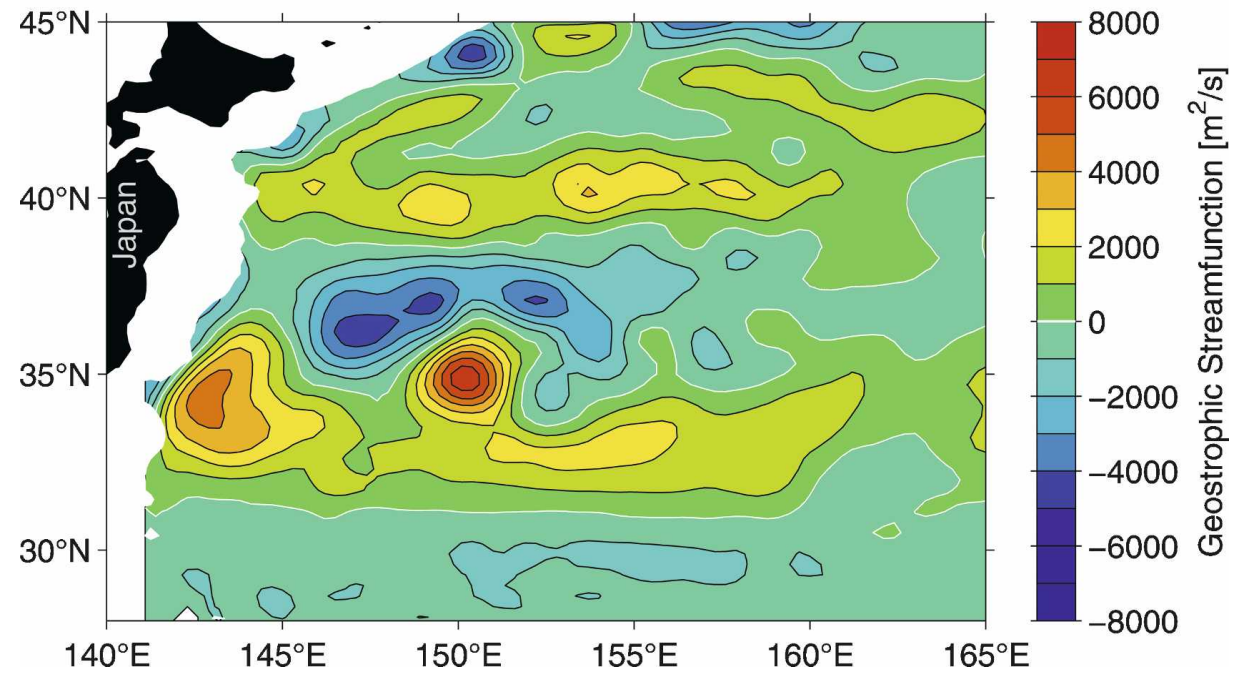

FIG. 9. Distributions of (a) the depth and (b) the mean geostrophic streamfunction $\bar{\Psi}$ on the $27.575 \sigma_{\theta}$ surface. Averaged in 2000-04 from the OFES hindcast run.

streamfunction can be solved by integrating the rhs of Eq. (3) pseudowestward along constant $\bar{Q}$ contours:

$$
\frac{\partial \bar{\Psi}}{\partial p}=-\nabla \cdot\left(\overline{\mathbf{u}^{\prime} Q^{\prime}}\right)
$$

where $p$ is the arc length along the constant $\bar{Q}$ contour, rescaled according to $\partial|\mathbf{x}| / \partial p=|\nabla \bar{Q}|$ (Rhines and Holland 1979). Here the integration is taken pseudowestward because the large-scale $\nabla \bar{Q}$, as shown in Fig. 10, is directed northward. Figure 14 shows the $\bar{\Psi}$ field derived from Eq. (5) using the $-\boldsymbol{\nabla} \cdot\left(\overline{\mathbf{u}^{\prime} Q^{\prime}}\right)$ values shown in Fig. $12 \mathrm{~b}$ and $p=0$ along $165^{\circ} \mathrm{E}$. Notice that by integrating along the constant $\bar{Q}$ contours, many of the small-scale features in the eddy PV flux convergence field are smoothed out and the resultant $\bar{\Psi}$ pattern exhibits broader spatial scales. Compared to the "true" $\bar{\Psi}$ field of Fig. 9b, the inferred $\bar{\Psi}$ field shown in Fig. 14 generally has the correct sign and this is particularly true in regions of the northern RG and the subarctic boundary. Overall, the inferred $\bar{\Psi}$ values have larger amplitudes than those shown in Fig. 9b, suggesting that the eddy-induced mean circulation is likely weakened by the dissipation processes neglected in the turbulent Sverdrup balance, Eq. (3). This result is consistent with the findings in Figs. 12 and 13 that $J(\bar{\Psi}, \bar{Q})$ and $-\boldsymbol{\nabla} \cdot\left(\overline{{\overline{u^{\prime}}}^{\prime}}\right)$ are not exactly balanced. 


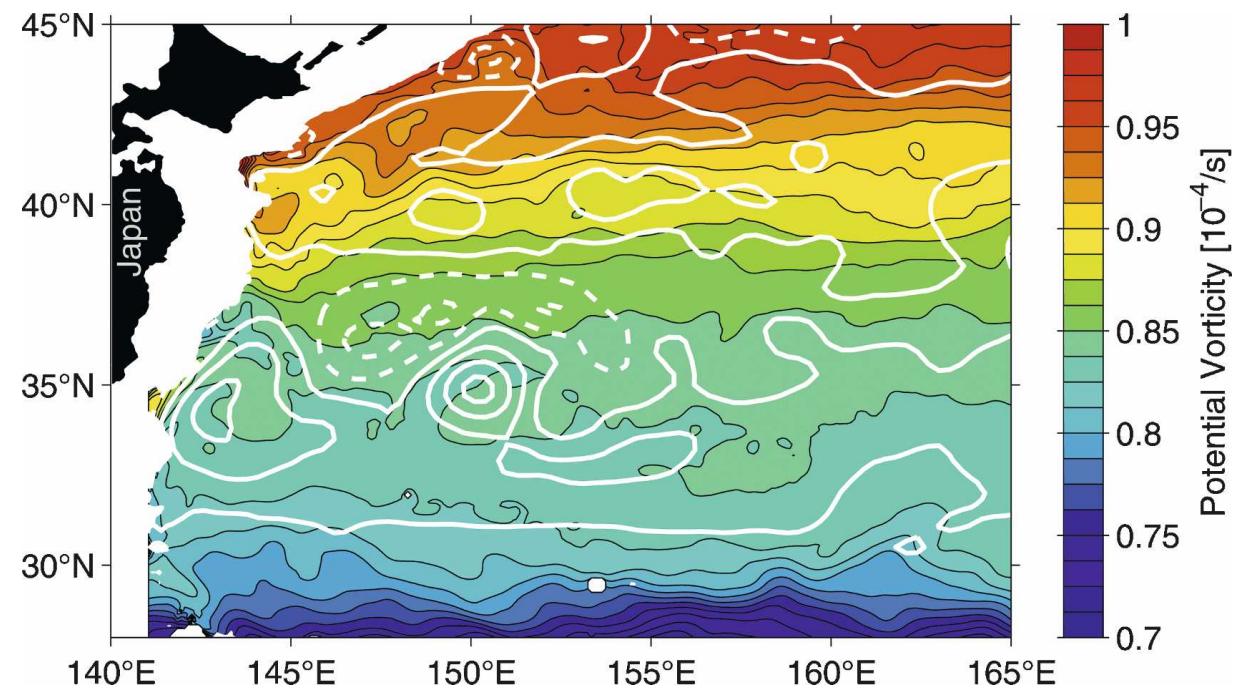

FIG. 10. Distribution of the mean potential vorticity $\bar{Q}$ on the $27.575 \sigma_{\theta}$ surface. Averaged in 2000-04 from the OFES hindcast run. White contours denote the geostrophic streamfunctions shown in Fig. 9b.

Finally, we note that the mean KE jet itself cannot be entirely explained by horizontal convergence of the eddy PV fluxes; the inferred streamfunction values along the mean path of the KE jet appear not well organized in Fig. 14. One possibility for this is that the mean KE jet at the $27.575 \sigma_{\theta}$ level is not purely eddy driven but is also influenced by the large-scale wind forcing.

\section{Summary}

Over the past several years, a large number of profiling floats have been deployed in the western North
Pacific Ocean as part of the Kuroshio Extension System Study (KESS) and the International Argo program. Using the drift information from these floats at their parking depths, we examined the regional mean circulation at the $1500-\mathrm{m}$ depth. The float-inferred mean flow field confirmed several middepth circulation features that have been noted in previous observations: for example, the existence of the deep, meandering KE jet, its northeastward branching upstream of the Shatsky Rise, and the intense RG south of the KE jet. The float measurements also revealed new circulation features at the 1500-m depth. In particular, a well-defined RG is found

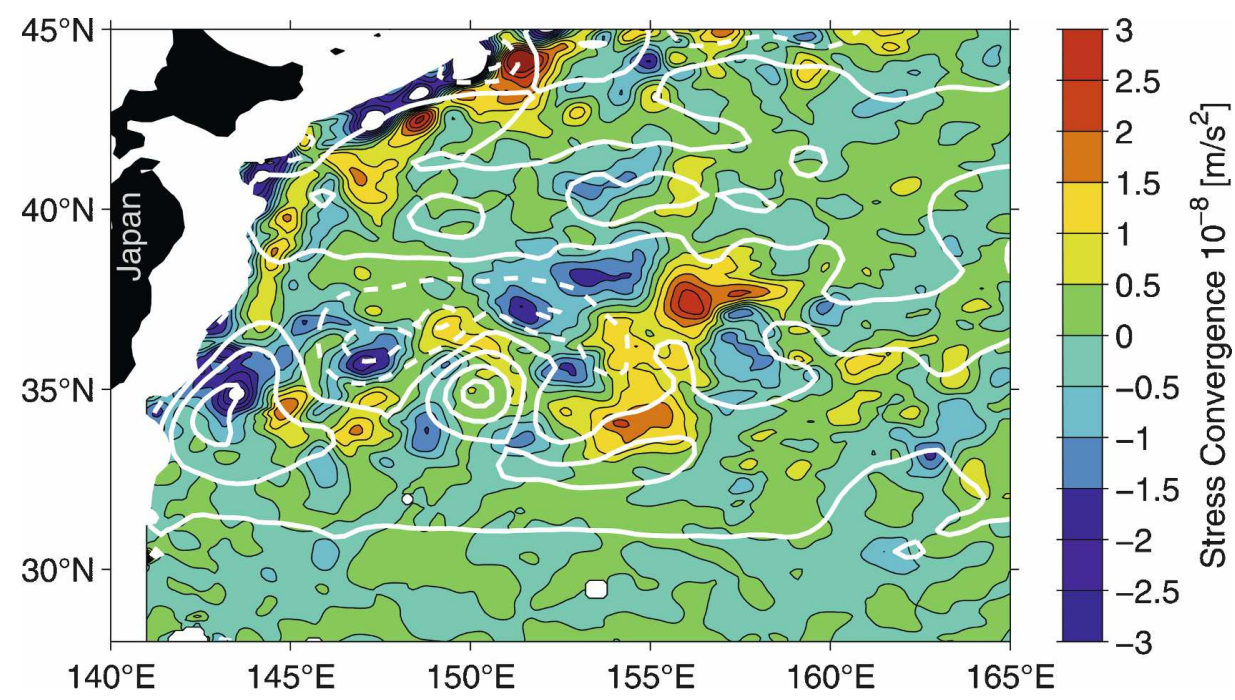

FIG. 11. Distribution of the Reynolds stress convergence, $-\boldsymbol{\nabla} \cdot\left(\overline{u^{\prime} \mathbf{u}^{\prime}}\right)$, on the $27.575 \sigma_{\theta}$ surface. Averaged in 2000-04 from the OFES hindcast run. White contours denote the geostrophic streamfunctions shown in Fig. 9b. 
(a) Mean PV Advection $\left[1 \times 10^{-12} \mathrm{~s}^{-2}\right]$

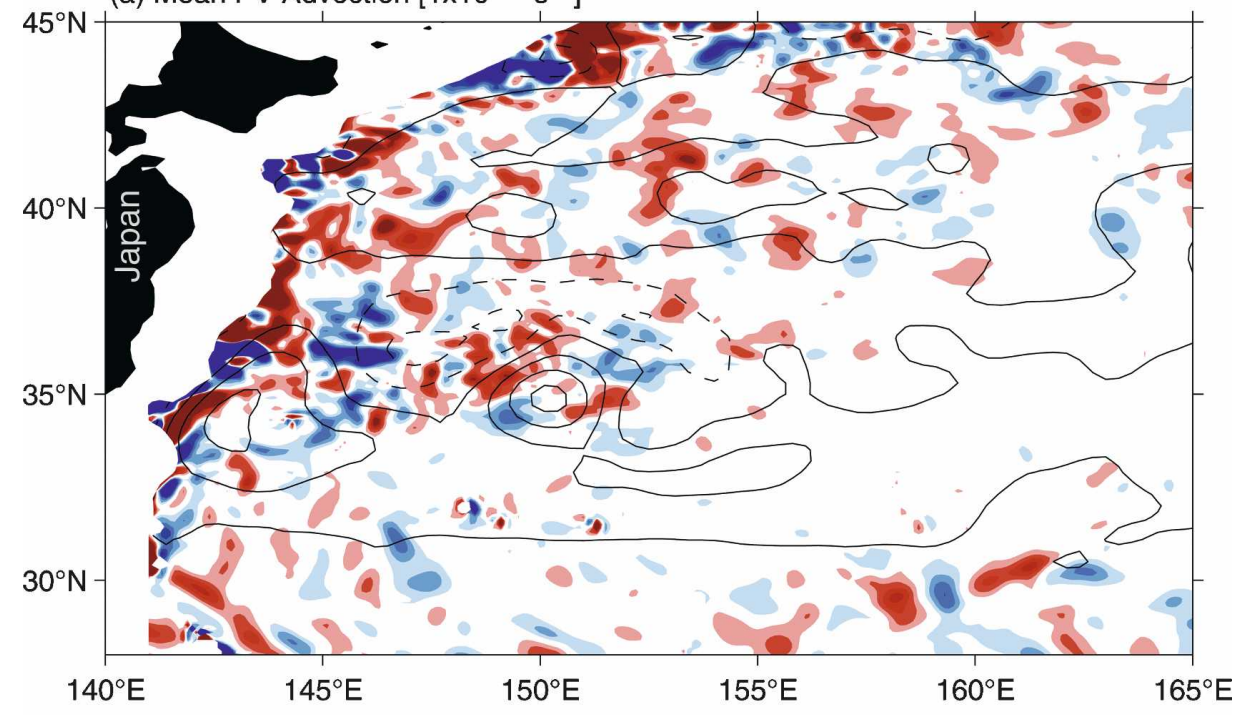

(b) Eddy PV Flux Convergence $\left[1 \times 10^{-12} \mathrm{~s}^{-2}\right]$

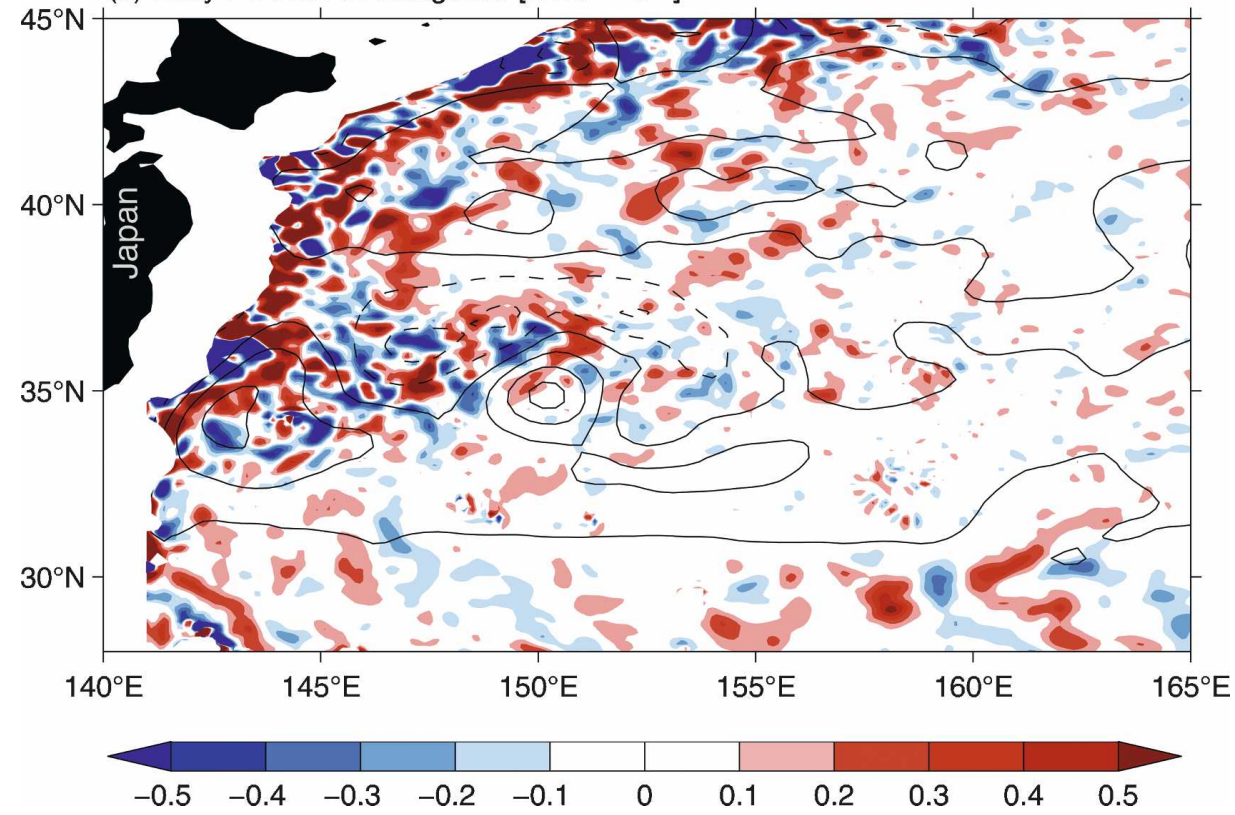

FIG. 12. Distributions of (a) the mean PV advection, $J(\bar{\Psi}, \bar{Q})$, and (b) the eddy PV flux convergence, $-\boldsymbol{\nabla} \cdot\left(\overline{\mathbf{u}^{\prime} Q^{\prime}}\right)$ on the $27.575 \sigma_{\theta}$ surface. Averaged in 2000-04 from the OFES hindcast run. Black contours denote the geostrophic streamfunctions shown in Fig. 9 b.

to exist north of the KE jet: spatially, it spans from east of the Japan Trench at $\sim 145^{\circ} \mathrm{E}$ to west of the Shatsky Rise at $\sim 156^{\circ} \mathrm{E}$ and is confined to the north by the subarctic boundary along $40^{\circ} \mathrm{N}$. Although westwardrecirculating flows have been observed north of the KE jet in the past, the float results presented in this study provide the first observational picture of the spatial pattern of the mean northern RG.

The presence of the deep-reaching, eastward-flowing subarctic boundary and northeastward-flowing Sub- arctic Front is another new middepth circulation feature revealed by the float measurements. Both of these currents have been regarded heretofore as "shallow" circulation features in the western subarctic gyre of the North Pacific Ocean. In addition, a continuous northward flow is found to exist offshore of the southwardflowing Oyashio; it overrides the eastern flank of the Japan Trench and delineates the western end of the northern RG.

Notice that the linear Sverdrup dynamics predicts 


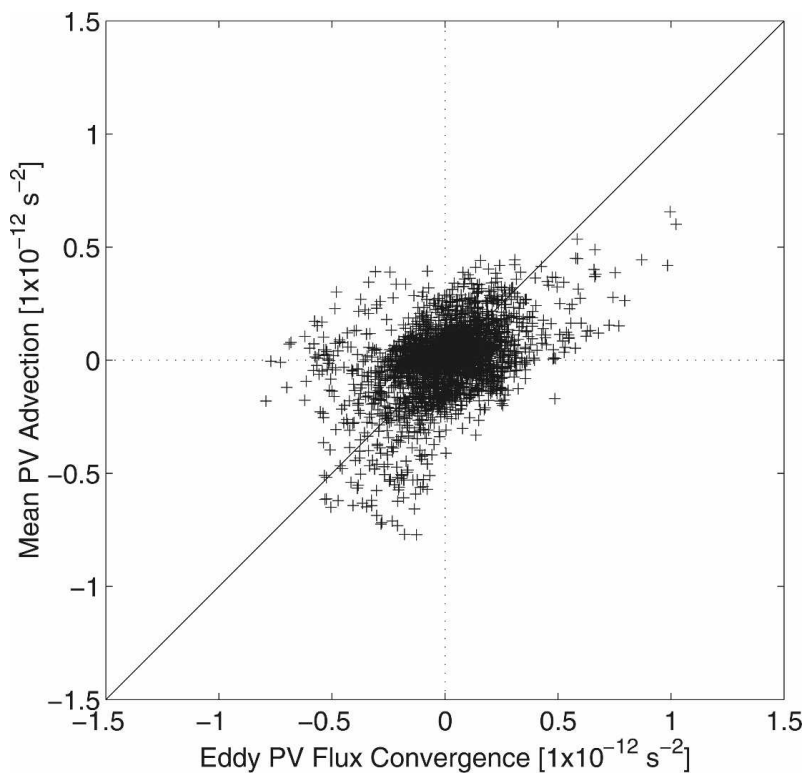

FIG. 13. Scatterplot of $J(\bar{\Psi}, \bar{Q})$ vs $-\nabla \cdot\left(\overline{\mathbf{u}^{\prime} Q^{\prime}}\right)$ inside the KE's northern RG. Here, the northern RG is defined by the area where $\bar{\Psi}<1000 \mathrm{~m}^{2} \mathrm{~s}^{-1}$ in Fig. 9b. The linear correlation coefficient between the two terms is 0.45 .

that the wind-driven, subtropical western boundary current (i.e., the Kuroshio) should separate from the coast of Japan at $\sim 42^{\circ} \mathrm{N}$. That the actual separation of the $\mathrm{KE}$ jet occurs at $\sim 35^{\circ} \mathrm{N}$ is a direct consequence of the presence of the northern RG. By causing the KE jet to separate at a southerly latitude, the northern RG creates an intergyre area, commonly known as the "Mixed Water Region," within which the subtropical- and subarctic-origin waters are mixed and transformed (e.g., Talley 1993; Yasuda et al. 1996).

With the bottom topography underlying the KE's northern RG essentially flat, we hypothesized that the northern RG is driven by eddy fluxes associated with the time-varying $\mathrm{KE}$ jet. To test this forcing mechanism, we analyzed the output from the OGCM for the Earth Simulator (OFES) hindcast run. The OFES hindcast model is eddy resolving and it simulates well the middepth circulation features inferred from the float measurements. An examination of the time-mean $x$ momentum balance in the OFES hindcast run revealed that the Reynolds stress convergence worked to accelerate westward zonal mean flows on the two flanks of the meandering KE jet, consistent with our hypothesis that the northern $\mathrm{RG}$ is driven by radiating eddy fluxes. While the calculation of the Reynolds stress convergence helps determine the direction of the accelerating mean flow, it provides little information on the strength of the resulting mean circulation. To evaluate this latter quantity, we evaluated the horizontal convergence of eddy PV fluxes based on the OFES hindcast run. By applying the turbulent Sverdrup balance equation, we found that the convergent eddy PV fluxes alone tended to overestimate the resultant northern RG and that the eddy dissipation processes are likely to play a role in controlling the strength of the spunup northern RG.

In the OFES hindcast run, the KE's northern RG has a maximum volume transport of $26.4 \mathrm{~Sv}$ near $150^{\circ} \mathrm{E}$ and its presence as an equivalent-barotropic gyre appears to persist on the interannual and longer time scales. As the dynamic state of the KE system undergoes clear

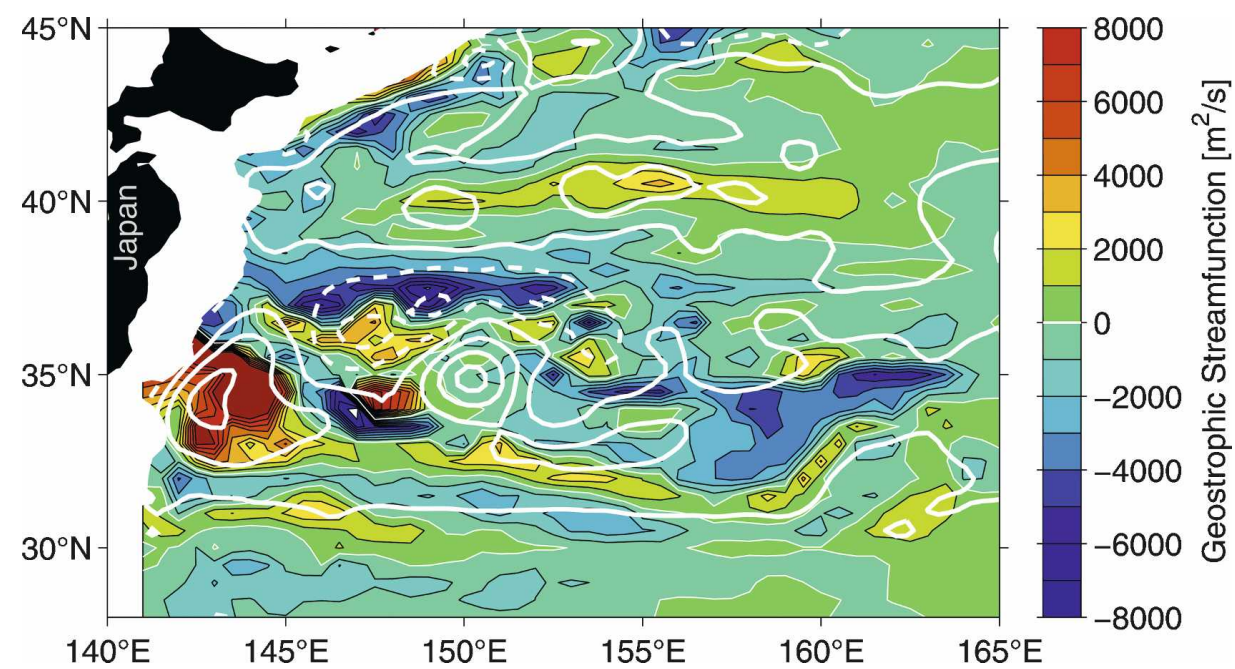

FIG. 14. Distribution of the geostrophic streamfunction inferred from the turbulent Sverdrup balance, Eq. (3), on the $27.575 \sigma_{\theta}$ surface. White contours denote the geostrophic streamfunctions shown in Fig. 9b. 
stable and unstable cycles (e.g., Qiu and Chen 2005; Taguchi et al. 2007), it will be interesting in future analyses of the profiling float data to clarify the timevarying nature of the northern $\mathrm{RG}$.

Acknowledgments. This study benefited from collaboration with the other KESS principal investigators: Meghan Cronin, Kathy Donohue, Humio Mitsudera, Randy Watts, and Shang-Ping Xie. Discussions with Nikolai Maximenko and Niklas Schneider, and detailed comments made by the anonymous reviewers, helped improve an early version of the manuscript. The international Argo profiling float data used in this study were provided by the U.S.-GODAE Argo Global Data Assembly Center. The OFES simulation was conducted on the Earth Simulator under the support of JAMSTEC and its output was made available via the IPRC's Asia-Pacific Data-Research Center. This study was supported by NSF through Grant OCE-0220680 (UH) and OCE-0220161 (WHOI).

\section{REFERENCES}

Berloff, P., A. M. Hogg, and W. K. Dewar, 2007: The turbulent oscillator: A mechanism of low-frequency variability of the wind-driven ocean gyres. J. Phys. Oceanogr., 37, 2362-2386.

Bretherton, F. R., R. E. Davis, and C. B. Fandry, 1976: A technique for objective analysis and design of oceanographic experiments applied to MODE-73. Deep-Sea Res., 23, 559-581.

Chen, S., B. Qiu, and P. Hacker, 2007: Profiling float measurements of the recirculation gyre south of the Kuroshio Extention in May to November 2004. J. Geophys. Res., 112, C05023, doi:10.1029/2006JC004005.

Conkright, M. E., R. A. Locarnini, H. E. Garcia, T. D. O’Brien, T. P. Boyer, C. Stephens, and J. I. Antonov, 2002: World Ocean Atlas 2001: Objective analyses, data statistics, and figures, CD-ROM documentation. National Oceanographic Data Center, Silver Spring, MD, 17 pp.

Dewar, W. K., 2003: Nonlinear midlatitude ocean adjustment. $J$. Phys. Oceanogr., 33, 1057-1082.

Fujio, S., and D. Yanagimoto, 2005: Deep current measurements at $38^{\circ} \mathrm{N}$ east of Japan. J. Geophys. Res., 110, C02010, doi:10.1029/2004JC002288.

Greatbatch, R. J., A. F. Fanning, and A. D. Goulding, 1991: A diagnosis of interpentadal circulation changes in the North Atlantic. J. Geophys. Res., 96, 22 009-22 023.

Hogg, A. M., P. D. Killworth, J. R. Blundell, and W. K. Dewar, 2005: Mechanisms of decadal variability of the wind-driven ocean circulation. J. Phys. Oceanogr., 35, 512-531.

Hogg, N. G., 1988: Stochastic wave radiation by the Gulf Stream. J. Phys. Oceanogr., 18, 1687-1701.

- 1992: On the transport of the Gulf Stream between Cape Hatteras and the Grand Banks. Deep-Sea Res., 39, 1231-1246.

— R. S. Pickart, R. M. Hendry, and W. Smethie, 1986: On the northern Recirculation gyre of the Gulf Stream. Deep-Sea Res., 33, 1139-1166.

Holland, W. R., and P. B. Rhines, 1980: An example of eddyinduced ocean circulation. J. Phys. Oceanogr., 10, 1010-1031.

Hurlburt, H. E., and E. J. Metzger, 1998: Bifurcation of the Kuro- shio Extension at the Shatsky Rise. J. Geophys. Res., 103, 7549-7566.

Jayne, S. R., N. G. Hogg, and P. Malanotte-Rizzoli, 1996: Recirculation gyres forced by a beta-plane jet. J. Phys. Oceanogr., 26, 492-504.

Joyce, T. M., and W. J. Schmitz, 1988: Zonal velocity structure and transport in the Kuroshio Extension. J. Phys. Oceanogr., 18, 1484-1494.

Kawai, H., 1972: Hydrography of the Kuroshio Extension. Kuroshio-Its Physical Aspects, H. Stommel and K. Yoshida, Eds., University of Tokyo Press, 235-354.

Kistler, R., and Coauthors, 2001: The NCEP-NCAR 50-Year Reanalysis: Monthly means CD-ROM and documentation. Bull. Amer. Meteor. Soc., 82, 247-267.

Kono, T., and Y. Kawasaki, 1997: Results of CTD and mooring observations southeast of Hokkaido: 1 . Annual velocity and transport variations in the Oyashio. Bull. Hokkaido Natl. Fish. Res. Inst., 61, 65-81.

Mitsudera, H., B. Taguchi, Y. Yoshikawa, H. Nakamura, T. Waseda, and T. Qu, 2004: Numerical study on the Oyashio water pathways in the Kuroshio-Oyashio confluence. J. Phys. Oceanogr., 34, 1174-1196.

Mizuno, K., and W. B. White, 1983: Annual and interannual variability in the Kuroshio Current system. J. Phys. Oceanogr., 13, 1847-1867.

Nakamura, M., and Y. Chao, 2000: Characteristics of three-dimensional quasi-geostrophic transient eddy propagation in the vicinity of a simulated Gulf Stream. J. Geophys. Res., 105, 11 385-11 406.

Niiler, P. P., N. A. Maximenko, G. G. Panteleev, T. Yamagata, and D. B. Olson, 2003: Near-surface dynamical structure of the Kuroshio Extension. J. Geophys. Res., 108, 3193, doi:10.1029/2002JC001461.

Nonaka, M., H. Nakamura, Y. Tanimoto, T. Kagimoto, and H. Sasaki, 2006: Decadal variability in the Kuroshio-Oyashio Extension simulated in an eddy-resolving OGCM. J. Climate, 19, 1970-1989.

Owens, W. B., and B. A. Warren, 2001: Deep circulation in the northwest corner of the Pacific Ocean. Deep-Sea Res., 48, 959-993.

Park, J. J., K. Kim, B. A. King, and S. C. Riser, 2005: An advanced method to estimate deep currents form profiling floats. $J$. Atmos. Oceanic Technol., 22, 1294-1304.

Pierini, S., 2006: A Kuroshio Extension system model study: Decadal chaotic self-sustained oscillations. J. Phys. Oceanogr., 36, 1605-1625.

Qiu, B., and W. Miao, 2000: Kuroshio path variations south of Japan: Bimodality as a self-sustained internal oscillation. $J$. Phys. Oceanogr., 30, 2124-2137.

- , and S. Chen, 2005: Variability of the Kuroshio Extension jet, recirculation gyre, and mesoscale eddies on decadal timescales. J. Phys. Oceanogr., 35, 2090-2103.

—, P. Hacker, S. Chen, K. A. Donohue, D. R. Watts, H. Mitsudera, N. G. Hogg, and S. R. Jayne, 2006: Observations of the Subtropical Mode Water evolution from the Kuroshio Extension System Study. J. Phys. Oceanogr., 36, 457-473.

_ S. Chen, and P. Hacker, 2007: Effect of mesoscale eddies on Subtropical Mode Water variability from the Kuroshio Extension System Study (KESS). J. Phys. Oceanogr., 37, 9821000.

Rhines, P. B., and W. R. Holland, 1979: A theoretical discussion of eddy-driven mean flows. Dyn. Atmos. Oceans, 3, 289-325. 
Richardson, P. L., 1985: Averaged velocity and transport of the Gulf Stream near $55^{\circ}$ W. J. Mar. Res., 43, 83-111.

Sasaki, H., M. Nonaka, Y. Masumoto, Y. Sasai, H. Uehara, and H. Sakuma, 2008: An eddy-resolving hindcast simulation of the quasi-global ocean from 1950 to 2003 on the Earth Simulator. High Resolution Numerical Modelling of the Atmosphere and Ocean, W. Ohfuchi and K. Hamilton, Eds., Springer, in press.

Schmeits, M. J., and H. A. Dijkstra, 2001: Bimodal behavior of the Kuroshio and the Gulf Stream. J. Phys. Oceanogr., 31, 34353456.

Schmitz, W. J., 1987: Observation of new, large, and stable abyssal currents at mid-latitudes along $165^{\circ}$ E. J. Phys. Oceanogr., 17, 1309-1315.

_ , P. P. Niiler, and C. J. Koblinsky, 1987: Two-year moored instrument results along $152^{\circ}$ E. J. Geophys. Res., 92, $10826-$ 10834.

Smith, W. H. F., and D. T. Sandwell, 1994: Bathymetric prediction from dense altimetry and sparse shipboard bathymetry. $J$. Geophys. Res., 99, 21 803-21 824.

Spall, M. A., 1996: Dynamics of the Gulf Stream/deep western boundary current crossover. Part II: Low-frequency internal oscillations. J. Phys. Oceanogr., 26, 2169-2182.

Taguchi, B., S.-P. Xie, N. Schneider, M. Nonaka, H. Sasaki, and Y. Sasai, 2007: Decadal variability of the Kuroshio Extension: Observations and an eddy-resolving model hindcast. J. Climate, 20, 2357-2377.
Talley, L. D., 1988: Potential vorticity distribution in the North Pacific. J. Phys. Oceanogr., 18, 89-106.

- 1993: Distribution and formation of North Pacific Intermediate Water. J. Phys. Oceanogr., 23, 517-537.

Vallis, G. K., 2006: Atmospheric and Oceanic Fluid Dynamics. Cambridge University Press, 745 pp.

Wijffels, S. E., M. M. Hall, T. M. Joyce, D. J. Torres, P. Hacker, and E. Firing, 1998: Multiple deep gyres of the western North Pacific: A WOCE section along $149^{\circ}$ E. J. Geophys. Res., 103, 12 985-13 009.

Worthington, L. V., 1976: On the North Atlantic circulation. Johns Hopkins Oceanogr. Stud., 6, 110 pp.

Yasuda, I., 2003: Hydrographic structure and variability in the Kuroshio-Oyashio transition area. J. Oceanogr., 59, 389-402.

_ K. Okuda, and Y. Shimizu, 1996: Distribution and modification of North Pacific Intermediate Water in the KuroshioOyashio interfrontal zone. J. Phys. Oceanogr., 26, 448-465.

Yoshikawa, Y., J. A. Church, H. Uchida, and N. J. White, 2004: Near bottom currents and their relation to the transport in the Kuroshio Extention. Geophys. Res. Lett., 31, L16309, doi:10.1029/2004GL020068.

Zhang, R., and G. K. Vallis, 2007: The role of bottom vortex stretching on the path of the North Atlantic western boundary current and on the northern recirculation gyre. J. Phys. Oceanogr., 37, 2053-2080. 